\title{
Viabilidade econômica para implantação de área de escape
}

Economic viability for deployment of escape lane

\section{Cláudio Roberto da Motta Câmara ${ }^{1 *}$; Rodrigo Peixoto da Silva²; Newton Walter Gava ${ }^{3}$}

${ }^{1 *}$ Autopista Litoral Sul S.A. - Engenheiro Civil Coordenador de Projetos - Av. Santos Dumont, 935, 2º andar - Santo Antônio - 89218-105 - Joinville, SC - Brasil <claudio@ doceartebrasil.com.br>

${ }^{2}$ Escola Superior de Agricultura "Luiz de Queiroz" (ESALQ/USP) - Doutorando do Programa de Pós-Graduação em Economia Aplicada (PPGEA) - Av. Pádua Dias, 11 Bairro Agronomia - 13418-900 - Piracicaba, SP - Brasil

${ }^{3}$ NK Engenharia S/C Ltda. - Engenheiro Mecânico Sócio Diretor - Rua Humberto I, 298 - Vila Mariana - 04018-031 - São Paulo, SP - Brasil

\section{Resumo}

Investir em segurança para salvar vidas é uma ação perfeitamente alinhada às premissas estipuladas pela Resolução no 2/2009 da Organização das Nações Unidas. Com base nesse contexto, este trabalho teve como objetivo avaliar a viabilidade econômica de uma área de escape em uma rodovia brasileira. O trabalho utilizou dados reais de acidentes e custos estimados para implantação/manutenção desta área de escape. A avaliação foi realizada através de indicadores tradicionais de análise de viabilidade econômica, considerando um fluxo de caixa de 16 anos. O projeto se mostrou amplamente satisfatório, visto que o Payback seria atingido relativamente rápido e o Valor Presente Líquido e Taxa Interna de Retorno foram positivos e elevados. Além disso, o índice B/C foi muito superior a 1, demonstrando que o projeto proposto detém alta viabilidade econômica. No entanto, pesquisas futuras devem-se considerar possíveis soluções técnicas de engenharia alternativas e, sempre que possível, compará-las.

Palavras-chave: BR-376, dispositivos de segurança, rodovia, tráfego

\begin{abstract}
Investing in security to save lives is an action perfectly aligned with premises laid down by resolution $n^{\circ}$ 2/2009 of the United Nations. Based on this context, this work evaluated the economic viability of an escape lane in a Brazilian highway, which could save countless lives. The work used actual accident data and estimated costs for the Project. The methodology calculated costs (deployment/maintenance) and benefits (accidents avoided). The evaluation was constructed by traditional indicators of economic viability analysis, considering a cash flow of 16 years. The project was largely satisfactory, Payback is reached relatively fast and the Net Present Value and Internal Rate of Return were positive and high. In addition, the index B/C was far superior to 1 , demonstrating that the proposed Project holds high economic viability. However, further researches should be aware on other possible solutions and engineering techniques to compare them.
\end{abstract}

Keywords: BR-376, safety devices, highway, traffic

\section{Introdução}

O eixo rodoviário brasileiro composto pelo segmento das rodovias BR-376/PR, do $\mathrm{km} 614$ ao $\mathrm{km}$ 682, e pela BR-101/SC, do km 0 ao $\mathrm{km} \mathrm{218,} \mathrm{é} \mathrm{um} \mathrm{dos} \mathrm{segmentos}$ rodoviários mais carregados em termos de volumes de tráfego, como pode ser constatado no relatório de 2016 do Plano Nacional de Contagem de Tráfego (DNIT, 2016). Existe, nesse segmento, um trecho de serra entre o km 663 e o km 671 da BR-376/PR que detém uma geometria horizontal e vertical bastante adversa com relação às condições de segurança desejáveis. Além disso, o trecho é precedido por $49 \mathrm{~km}$ de rodovia conduzidos com velocidade de $110 \mathrm{~km} \mathrm{~h}-1$, indo de Curitiba até o alto da serra da represa da Voçoroca.

Esses $8 \mathrm{~km}$ de pista na descida da serra são caracterizados por uma grande sequência de curvas
(22 curvas) na qual 68,18\% delas possui raio inferior ao mínimo $($ Rmín $=230 \mathrm{~m})$ necessário para percorrêlas com velocidade de $80 \mathrm{~km} \mathrm{h-1} \mathrm{em} \mathrm{uma} \mathrm{taxa} \mathrm{máxima}$ de superelevação de 8\% (DNIT, 1999). Para agravar a situação, a inclinação média da rampa (pista) de descida desta serra é, ainda de acordo com DNIT (1999), de $5,3 \%$, o que acaba induzindo o motorista a trafegar em alta velocidade devido ao efeito gravitacional e, ao mesmo tempo, as sequências de curvas fechadas obrigam os motoristas a trafegar todo esse trecho sobrecarregando os sistemas de freios ou mesmo realizando frenagens bruscas ou que causem o bloqueio das rodas.

Tais características levam, com frequência, os veículos pesados ao ponto de fadiga de seus sistemas de freio, fazendo com que percam sua eficácia devido ao superaquecimento - efeito Fade ou Fading - (Fukuchi et al., 2015), ocasionando, muitas vezes, graves acidentes. 
Este trecho rodoviário de serra detém um crítico quadro estatístico de acidentes graves e fatais (Arteris, 2016), originados tanto pela irresponsabilidade e inexperiência de motoristas, como pelas más condições mecânicas e falta de manutenção adequada dos caminhões. Ainda de acordo com os dados da concessionária, a média de acidentes por excesso de velocidade, por desrespeito à sinalização e por perda dos freios devido ao superaquecimento neste trecho de rodovia - $\mathrm{km} 663$ ao $\mathrm{km} 671$ - foi da ordem de 58 acidentes/ano entre 2006 e 2008 e da ordem de 26 acidentes/ano de 2008 até 2015. A redução na média de acidentes/ano após 2008 ocorreu após o início do sistema de concessão rodoviária deste trecho da BR-376, que promoveu inúmeros melhoramentos físicos, além de criar e implantar um plano especial de sinalização horizontal e vertical para os seus diversos pontos críticos (Arteris, 2016).

Não obstante aos diversos melhoramentos implantados pela concessionária, as taxas de acidentes não se anularam, conforme os dados supracitados e conforme foi possível verificar em Arteris (2016) e Arteris (2006). A sinalização ostensiva implantada tem um potencial de minimizar os acidentes oriundos do excesso de velocidade e relacionados à falta de sinalização. Os acidentes oriundos da inadequada manutenção dos caminhões, da inexperiência dos condutores e da irresponsabilidade pela não utilização do freio motor nas descidas, por sua vez, necessitam de outros tipos de medida para que deixem de vitimar motoristas e passageiros inocentes.

A Organização das Nações Unidas [ONU] e Organização Mundial da Saúde [OMS] lançaram, no ano de 2009, a campanha Década De Ação Pela Segurança No Trânsito - 2011-2020 (ONU, 2011), na qual estipulou-se como meta o índice de redução de 50\% de acidentes em 10 anos, por meio de ações eficientes dos governos em todos os níveis e âmbitos de competência governamental (WHO, 2016).

Imbuído pela motivação dessa campanha da ONU, este trabalho avaliou a viabilidade econômica para a implantação de uma área de escape nessa região crítica, especificamente no trecho do km 667+300 da BR-376/ PR, visando salvar a vida de um grande número de caminhoneiros.

Outros estudos relevantes e correlatos à implantação de áreas de escape a serem destacados são Hirai (2015), sobre o "Projeto Executivo da Área de Escape do km 353+000 da BR-116" e Gava (2016), com seus dois "Estudos de tráfego para análise da seção operacional da pista na aproximação da Área de Escape do km $667+300$ e do km 673+300 da BR-376". Os quatro estudos citados permeiam pela viabilidade técnica, com a avaliação dos possíveis tipos de áreas, necessidade de instalação, definição de sua localização no segmento estudado, dimensionamento físico e diretrizes para a operação, porém não abordam a viabilidade econômica das áreas de escape.

Este trabalho parte do entendimento de que o uso da solução de áreas de escape para mitigar acidentes oriundos da perda do sistema de freios de veículos pesados é absolutamente viável tecnicamente e de uso consagrado mundialmente. Desta forma, concentrou-se em avaliar a viabilidade econômica de uso de uma área de escape como solução para um problema de um local específico de uma rodovia federal.

\section{Material e Métodos}

A metodologia de cálculo de viabilidade econômica acompanhou a linha de raciocínio de Gold (1998), que apresenta quatorze passos para o cálculo de viabilidade econômica de obras de infraestrutura, abordando o cálculo de vida útil, custos de implantação, custos anuais de manutenção, fluxo dos custos de implantação e manutenção, custo médio anual dos acidentes de trânsito, valor da redução de acidentes de todos os anos do projeto e valores presentes dos custos e benefícios nas formas anuais e totais.

Em seus cinco passos finais foram apresentados os cálculos de indicadores tradicionais de análise de viabilidade econômica, como o Valor Presente Líquido [VPL] do projeto, da Taxa Interna de Retorno [TIR] e o Período de Retorno [Payback], bem como a análise de sensibilidade. Os próximos sub-tópicos seguem os passos estabelecidos por Gold (1998).

\section{Custos}

A alternativa de implantação de área de escape como projeto mitigador de acidentes possui características de vida útil de longo prazo, definida entre 10 e 20 anos (Gold, 1998). Foi adotado como período de vida útil do projeto o mesmo prazo do respectivo contrato de concessão rodoviária, que se encerra em 16 anos.

Dada a existência de um projeto executivo da referida área de escape, desenvolvido pela concessionária responsável, foi adotado como custo de implantação o próprio valor da obra, que correspondeu ao montante de $\mathrm{R} \$$ 15.129.000,00. Os custos anuais de operação, manutenção e conservação também foram fornecidos pela concessionária com base em valores praticados em outra área de escape operada pela mesma concessionária (Tabela 1).

De posse dos custos de implantação e dos custos anuais de operação, manutenção e conservação, foi construída a Tabela 2, que elencou os gastos anuais em todo o horizonte temporal do projeto. 
Tabela 1. Custos de operação, manutenção e conservação da área de escape, em reais, em uma rodovia federal (em $\mathrm{R} \$$ de 2016)

\begin{tabular}{lrcc}
\hline \multicolumn{1}{c}{ Item } & Quantidade & $\begin{array}{c}\text { Custo } \\
\text { Unitário }\end{array}$ & $\begin{array}{c}\text { Custo } \\
\text { Anual }\end{array}$ \\
\hline $\begin{array}{l}\text { Operação mensal da } \\
\text { área de escape }\end{array}$ & 12 & $10.854,00$ & $130.248,00$ \\
$\begin{array}{l}\text { Manutenção anual } \\
\text { da área de escape }\end{array}$ & 1 & $39.613,82$ & $39.613,82$ \\
$\begin{array}{l}\text { Conservação } \\
\text { mensal da área de }\end{array}$ & 12 & $16.168,96$ & $194.027,52$ \\
escape & & & $363.889,34$ \\
\hline Custo Total & & & \\
\hline
\end{tabular}

Tabela 2. Fluxo dos custos anuais referente aos custos de operação, manutenção e conservação da área de escape, em reais, em uma rodovia federal

\begin{tabular}{|c|c|c|c|c|}
\hline Ano & $\begin{array}{l}\text { Ano/ } \\
\text { projeto }\end{array}$ & Implantação & $\begin{array}{c}\text { Operação, } \\
\text { manutenção } \\
\text { e } \\
\text { conservação }\end{array}$ & Custo total \\
\hline & & . & --- R\$ --- & ----- \\
\hline 2016 & 0 & $15.129 .000,00$ & 0,00 & $15.129 .000,00$ \\
\hline 2017 & 1 & 0,00 & $363.889,34$ & $363.889,34$ \\
\hline 2018 & 2 & 0,00 & $363.889,34$ & $363.889,34$ \\
\hline 2019 & 3 & 0,00 & $363.889,34$ & $363.889,34$ \\
\hline 2020 & 4 & 0,00 & $363.889,34$ & $363.889,34$ \\
\hline 2021 & 5 & 0,00 & $363.889,34$ & $363.889,34$ \\
\hline 2022 & 6 & 0,00 & $363.889,34$ & $363.889,34$ \\
\hline 2023 & 7 & 0,00 & $363.889,34$ & $363.889,34$ \\
\hline 2024 & 8 & 0,00 & $363.889,34$ & $363.889,34$ \\
\hline 2025 & 9 & 0,00 & $363.889,34$ & $363.889,34$ \\
\hline 2026 & 10 & 0,00 & $363.889,34$ & $363.889,34$ \\
\hline 2027 & 11 & 0,00 & $363.889,34$ & $363.889,34$ \\
\hline 2028 & 12 & 0,00 & $363.889,34$ & $363.889,34$ \\
\hline 2029 & 13 & 0,00 & $363.889,34$ & $363.889,34$ \\
\hline 2030 & 14 & 0,00 & $363.889,34$ & $363.889,34$ \\
\hline 2031 & 15 & 0,00 & $363.889,34$ & $363.889,34$ \\
\hline 2032 & 16 & 0,00 & $363.889,34$ & $363.889,34$ \\
\hline
\end{tabular}

O custo médio anual dos acidentes antes da implantação do projeto foi baseado na metodologia apresentada no extrato da pesquisa IPEA (2006), que contém parte do relatório executivo "Impactos sociais e econômicos dos acidentes de trânsito nas rodovias brasileiras" IPEA/DENATRAN/ANTP (2006). Os valores de custos médios utilizados foram extraídos da Tabela 11 deste extrato da pesquisa IPEA/DENATRAN/ANTP (2006). Os valores foram corrigidos pelo IPCA acumulado do período de jan/2006 a dez/2015 de 1,7719.

A pesquisa IPEA/DENATRAN/ANTP (2006) considerou os tipos de acidentes (sem vítima, com vítima e com fatalidade), número total de acidentes, estado das pessoas envolvidas (ilesos, leves, graves e mortos) e tipos de veículos envolvidos (automóvel, motocicleta, bicicleta, utilitário, caminhão, ônibus e outros).

As quantidades relacionadas ao número de acidentes, número de pessoas e veículos envolvidos em acidentes foram fornecidas pela concessionária e representam a média anual relativa aos dados estatísticos de agosto de 2011 a dezembro de 2015 e foram utilizados para calcular o custo anual dos acidentes, considerando a situação corrente do trecho: inexistência de área de escape. A tabela 3 resume o custo anual para cada tipo de acidentes antes da implantação do projeto proposto.

Incorre-se em um alto custo médio com os acidentes, que tende a ser crescente conforme a gravidade do evento. Ao somar esses custos médios atingiu a uma medida monetária de quão penalizada foi a sociedade por conta dos acidentes nesse trecho, além, é claro do número de vidas perdidas. A tabela 4 traz o somatório dos valores de custo anual dos acidentes antes de implantado o projeto proposto.

Cabe destacar que os custos anuais apresentados recaem como um ônus a ser pago pela sociedade brasileira através de seus tributos pagos ao governo. Desta forma, cada acidente evitado, além de salvar vidas, desonera os contribuintes ou permite que o Estado aplique esses recursos em outras áreas, trazendo melhorias para a população.

\section{Redução esperada de acidentes após a implantação do projeto}

A existência de uma área de escape semelhante à projetada permitiu a estimativa da redução do número de acidentes que seria obtida com a implantação do projeto. A Tabela 5 apresenta os custos médios anuais relativos à redução no total de acidentes. As quantidades relacionadas ao número de acidentes, número de pessoas e veículos envolvidos em acidentes foi baseada nas mesmas médias anuais de estatísticas de redução de acidentes de uma área de escape implantada e operando a $4 \mathrm{~km}$ do local estudado e que detém as mesmas características físicas, técnicas, operacionais e de tráfego.

Notou uma mudança expressiva no número de acidentes, que envolveram todas as modalidades, principalmente no caso de acidentes sem vítimas, que, embora sejam menos graves, foram mais numerosos $\mathrm{e}$ representaram parcela significativa dos custos. A tabela 6 ilustra o somatório dos valores de custo anual da redução de acidentes esperada para o primeiro ano após implantação do projeto proposto. 
Tabela 3. Custo médio anual dos acidentes rodoviários federais, de julho de 2004 a junho de 2005, por tipo de acidente, antes da implantação do projeto proposto (em R \$ de 2016)

\begin{tabular}{|c|c|c|c|c|c|c|}
\hline \multirow{3}{*}{ Parâmetros } & \multicolumn{6}{|c|}{ Tipo de acidente } \\
\hline & \multicolumn{2}{|c|}{ Sem vítima } & \multicolumn{2}{|c|}{ Com vítima } & \multicolumn{2}{|c|}{ Com fatalidade } \\
\hline & Quantidade & Custo & Quantidade & Custo & Quantidade. & Custo \\
\hline & & ----- R\$ ----- & & ------ R\$ ------ & & ------- R\$ ------- \\
\hline Número de acidentes $^{1}$ (A) & 211,68 & & 39,17 & & 2,49 & \\
\hline Total de pessoas envolvidas ${ }^{1}$ (B) & 328,28 & $394.557,41$ & 98,71 & $1.360 .520,42$ & 5,43 & 1.277.397,35 \\
\hline Total de veículos envolvidos ${ }^{1}(\mathrm{C})$ & 295 & $4.012 .995,06$ & 62,03 & $2.205 .781,84$ & 3,62 & $174.145,89$ \\
\hline Outros (D) & 211,68 & $106.192,62$ & 39,17 & $14.664,81$ & 2,49 & $1.799,42$ \\
\hline $\begin{array}{l}\text { Total dos custos médios anuais } \\
\mathrm{E}=\mathrm{B}+\mathrm{C}+\mathrm{D}\end{array}$ & & $4.513 .745,10$ & & $3.580 .967,08$ & & 1.453.342,66 \\
\hline $\begin{array}{l}\text { Custo médio de cada acidente } \\
\mathrm{F}=\mathrm{E} / \mathrm{A}\end{array}$ & & $21.323,44$ & & $91.421,17$ & & $583.671,75$ \\
\hline
\end{tabular}

Fonte: adapatado de IPEA/DENATRAN/ANTP (2006). Relativo a acidentes ocorridos nas rodovias federais de julho de 2004 a junho de 2005 Nota: ${ }^{1}$ Valores médios de 2011 a 2015

Tabela 4. Custo anual total dos acidentes sem o projeto proposto

\begin{tabular}{lrr}
\hline & Tipo de acidente & \multicolumn{1}{c}{ Totais } \\
\hline & & $-1.513 .745,10$ \\
Sem vítimas & $3.580 .967,08$ \\
Com vítimas & $1.453 .342,66$ \\
Com fatalidade & $9.548 .054,83$ \\
\hline Total
\end{tabular}

Fonte: adaptado de IPEA/DENATRAN/ANTP (2006)

Tabela 5. Custo médio anual de redução de acidentes rodoviários por tipo de acidente (em R\$ de 2016)

\begin{tabular}{|c|c|c|c|c|c|c|}
\hline \multirow{3}{*}{ Parâmetro } & \multicolumn{6}{|c|}{ Tipo de acidente } \\
\hline & \multicolumn{2}{|c|}{ Sem vítima } & \multicolumn{2}{|c|}{ Com vítima } & \multicolumn{2}{|c|}{ Com fatalidade } \\
\hline & Quantidade & Custo & Quantidade. & Custo & Quantidade. & Custo \\
\hline & & ----- R\$ ----- & & ------ R\$ ------- & & ----- R\$ ----- \\
\hline 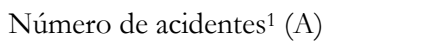 & 70,2 & & 19,7 & & 2,0 & \\
\hline Total de pessoas envolvidas ${ }^{1}$ (B) & 116,4 & $139.864,28$ & 46,4 & $897.275,46$ & 4,8 & $1.061 .170,60$ \\
\hline Total de veículos envolvidos ${ }^{1}(\mathrm{C})$ & 108,0 & $1.724 .458,76$ & 31,2 & $1.312 .976,01$ & 2,9 & $138.158,57$ \\
\hline Outros (D) & 70,2 & $35.206,91$ & 19,7 & $7.375,46$ & 2,0 & $1.474,23$ \\
\hline $\begin{array}{l}\text { Total dos custos médios anuais } \\
\mathrm{E}=\mathrm{B}+\mathrm{C}+\mathrm{D}\end{array}$ & & $1.899 .529,95$ & & $2.217 .626,93$ & & $1.200 .803,40$ \\
\hline $\begin{array}{l}\text { Custo médio de cada acidente }=\mathrm{F} \\
=\mathrm{E} / \mathrm{A}\end{array}$ & & $27.066,54$ & & $112.569,89$ & & $588.629,12$ \\
\hline
\end{tabular}

Fonte: adaptado de IPEA/DENATRAN/ANTP (2006)

Nota: ${ }^{1}$ Valores médios de 2011 a 2015 
Tabela 6. Custo anual da redução de acidentes esperada para o primeiro ano após implantação do projeto (em R \$ de 2016)

\begin{tabular}{lr}
\hline \multicolumn{1}{c}{ Tipo de acidente } & Totais \\
\hline & - $\$$-------- \\
Sem vítimas & $1.899 .529,95$ \\
Com vítimas & $2.217 .626,93$ \\
Com fatalidade & $1.200 .803,40$ \\
\hline Total & $5.317 .960,28$ \\
\hline
\end{tabular}

Fonte: adaptado de IPEA/DENATRAN/ANTP (2006)

A Tabela 7 apresenta os custos incorridos devido aos acidentes sem e com a implantação do projeto. Foi considerada a correção pela taxa anual de crescimento de tráfego de $6,2 \%$ constante no contrato de concessão da rodovia inerente ao local estudado neste trabalho (Arteris, 2016).

Tabela 7. Valor redução de acidentes esperada para cada ano da vida útil do projeto $^{1}$

\begin{tabular}{lrcr}
\hline Ano & Ano/projeto & $\begin{array}{c}\text { Custo dos } \\
\text { acidentes sem } \\
\text { projeto }\end{array}$ & $\begin{array}{c}\text { Benefícios: redução } \\
\text { do custo de } \\
\text { acidentes }\end{array}$ \\
\hline 2016 & 0 & ------------- R\$ -------------- \\
2017 & 1 & $9.548 .054,83$ & $5.317 .960,28$ \\
2018 & 2 & $10.140 .034,23$ & $5.647 .673,82$ \\
2019 & 3 & $10.768 .716,35$ & $5.997 .829,59$ \\
2020 & 4 & $11.436 .376,77$ & $6.369 .695,03$ \\
2021 & 5 & $12.145 .432,12$ & $6.764 .616,12$ \\
2022 & 6 & $12.898 .448,92$ & $7.184 .022,32$ \\
2023 & 7 & $13.698 .152,75$ & $7.629 .431,70$ \\
2024 & 8 & $14.547 .438,22$ & $8.102 .456,47$ \\
2025 & 9 & $15.449 .379,39$ & $8.604 .808,77$ \\
2026 & 10 & $16.407 .240,91$ & $9.138 .306,91$ \\
2027 & 11 & $17.424 .489,85$ & $9.704 .881,94$ \\
2028 & 12 & $18.504 .808,22$ & $10.306 .584,62$ \\
2029 & 13 & $19.652 .106,33$ & $10.945 .592,87$ \\
2030 & 14 & $20.870 .536,92$ & $11.624 .219,63$ \\
2031 & 15 & $22.164 .510,21$ & $12.344 .921,25$ \\
2032 & 16 & $23.538 .709,84$ & $13.110 .306,36$ \\
\hline & & &
\end{tabular}

Nota: ${ }^{1}$ adotado taxa de crescimento de tráfego de $6,2 \%$ ao ano

\section{Indicadores de viabilidade econômica}

Conforme discutido anteriormente, foram analisados os indicadores tradicionais de análise de viabilidade econômica, sejam eles: Valor Presente Líquido [VPL]; Índice Benefício/Custo [B/C]; Taxa Interna de Retorno [TIR]; e Payback Descontado.

O VPL foi calculado pelo somatório da diferença entre benefícios e custos de um projeto ao longo de seu período de vida, descontados por uma taxa definida a priori, denominada Taxa Mínima de Atratividade [TMA], que representa o custo de oportunidade do capital investido. É expresso pela Eq. (1) a seguir apresentada:

$$
\mathrm{VPL}=\sum_{J=1}^{\mathrm{N}} \frac{\mathrm{Bj}-\mathrm{C} j}{(1+\mathrm{i})}-\mathrm{I}-\mathrm{Io} ; \quad \mathrm{j}=1,2, \ldots, \mathrm{N}
$$

onde, $\mathrm{N}$ : é o número total de períodos analisados; $\mathrm{Bj}-\mathrm{Cj}$ : é fluxo de caixa no período j; I0: é o fluxo de caixa no período 0 ou investimento inicial; i: é a taxa de desconto.

Caso o VPL seja positivo, o retorno obtido no projeto será maior que o investimento inicial, aumentando desta forma o ativo do investidor e demostrando que o projeto é viável. Caso seja igual à zero, o retorno obtido no projeto será igual à TMA, tornando indiferente implementar ou não o projeto. Caso o VPL seja negativo, o retorno obtido no projeto não pagará o investimento inicial, mostrando que o projeto é inviável.

$\mathrm{O}$ valor do índice $\mathrm{B} / \mathrm{C}$ é obtido pela divisão do valor presente total dos benefícios sobre o valor presente total dos custos. Este valor deve ser superior a um, demonstrando que os benefícios são maiores que os custos do projeto e que o investimento é viável.

A Taxa Interna de Retorno [TIR] é a taxa de desconto iguala valores presentes totais de benefícios e custos, o que significa que o valor presente líquido do projeto é igual a 0 e o índice de benefício/custo é igual a 1 . A TIR indica o retorno do projeto em porcentagem e é calculada através da Eq. (2) (Gold, 1998).

$$
\mathrm{TIR}=r \text {, tal que: } \mathrm{VPL}=\sum_{\mathrm{j}=0}^{\mathrm{n}} \frac{\mathrm{FCj}}{(1+\mathrm{r})^{\mathrm{j}}}=0 ; j=1,2, \ldots, \mathrm{n}
$$

onde, n: é o número total de períodos analisados; FCj: é fluxo de caixa no período j; r: é a taxa de desconto.

Cabe destacar que na fórmula acima a taxa de desconto $r$ é a incógnita a ser calculada, enquanto que no cálculo dos valores presentes dos custos e benefícios anuais e também no cálculo do índice B/C a taxa de desconto i (12\%) é um valor pré-definido condizente com investimentos no mercado financeiro atual. Entretanto, é necessário comparar a TIR com um valor que seja tratado como mínimo aceitável para saber se o projeto é satisfatório ou não. Desta forma, como foi considerado o valor $12 \%$ para os cálculos de VPL e B/C, o mesmo foi considerado como o mínimo aceitável.

O Payback descontado (período de retorno) representa o número de anos necessários para que os benefícios cubram os custos do projeto, sendo o mesmo calculado pelo somatório do valor acumulado dos benefícios menos os custos, em valores presentes.

Para projetos de infraestrutura rodoviária, com altos valores de investimento inicial, adota-se como valor desejável máximo de Payback a metade do tempo de vida 
útil do projeto (Gold, 1998). Neste caso, o Payback ideal é de 8 anos (ano limite).

Em alguns projetos, os resultados da avaliação econômica podem ser completamente alterados por pequenas mudanças nos valores de um ou alguns poucos parâmetros. A análise de sensibilidade é necessária nos casos em que a TIR está próxima ao valor mínimo aceitável (Gold, 1998).

\section{Resultados e Discussão}

Os resultados obtidos com base na análise de viabilidade e discute as principais implicações oriundas dessas informações. Todos os dados de entrada utilizados neste trabalho foram direta ou indiretamente vinculados ao projeto específico da área de escape analisada, portanto, qualquer generalização para outros casos deve ser realizada com a devida cautela e adequação. Ainda assim, isso não diminui a abrangência social dos resultados encontrados, uma vez que se tratam da análise de um problema público, que afeta diversos motoristas e cidadãos brasileiros e que demonstra um avanço no entendimento do assunto.

A Tabela 8 apresenta os fluxos de caixa baseados na taxa de atratividade adotada de $12 \%$ ao ano, assim como os resultados de VPL, TIR e Payback. Os benefícios descritos são aqueles ilustrados na Tabela 7, enquanto os custos se referem aos mesmos valores ilustrados na Tabela 2. A partir desses valores foram calculados o Fluxo de Caixa, o Fluxo de Caixa Descontado e o Fluxo de Caixa Descontado e Acumulado, que permitiram a obtenção dos indicadores de viabilidade.

Tabela 8. Indicadores de viabilidade econômica ${ }^{1}$

\begin{tabular}{|c|c|c|c|c|c|}
\hline Ano & Benefícios & Custos & Fluxo de Caixa & $\begin{array}{c}\text { Fluxo de Caixa } \\
\text { Descontado }\end{array}$ & $\begin{array}{c}\text { Fluxo de Caixa } \\
\text { Descontado } \\
\text { Acumulado }\end{array}$ \\
\hline \multicolumn{6}{|c|}{ - } \\
\hline 2016 & 0,00 & 15.129.000,00 & $-15.129 .000,00$ & $-15.129 .000,00$ & $-15.129 .000,00$ \\
\hline 2017 & $5.317 .960,28$ & $363.889,34$ & 4.954.070,94 & 4.423.277,63 & $-10.705 .722,38$ \\
\hline 2018 & $5.647 .673,82$ & $363.889,34$ & $5.283 .784,48$ & $4.212 .200,64$ & $-6.493 .521,74$ \\
\hline 2019 & $5.997 .829,59$ & $363.889,34$ & $5.633 .940,25$ & $4.010 .127,39$ & $-2.483 .394,35$ \\
\hline 2020 & $6.369 .695,03$ & $363.889,34$ & $6.005 .805,69$ & $3.816 .798,09$ & $1.333 .403,74$ \\
\hline 2021 & $6.764 .616,12$ & $363.889,34$ & $6.400 .726,78$ & $3.631 .944,27$ & 4.965.348,01 \\
\hline 2022 & 7.184.022,32 & $363.889,34$ & 6.820.132,98 & $3.455 .291,62$ & $8.420 .639,63$ \\
\hline 2023 & $7.629 .431,70$ & $363.889,34$ & $7.265 .542,36$ & $3.286 .562,39$ & $11.707 .202,02$ \\
\hline 2024 & $8.102 .456,47$ & $363.889,34$ & $7.738 .567,13$ & $3.125 .477,47$ & $14.832 .679,49$ \\
\hline 2025 & $8.604 .808,77$ & $363.889,34$ & $8.240 .919,43$ & $2.971 .758,16$ & $17.804 .437,65$ \\
\hline 2026 & $9.138 .306,91$ & $363.889,34$ & $8.774 .417,57$ & $2.825 .127,62$ & $20.629 .565,27$ \\
\hline 2027 & $9.704 .881,94$ & $363.889,34$ & $9.340 .992,60$ & $2.685 .312,16$ & $23.314 .877,44$ \\
\hline 2028 & $10.306 .584,62$ & $363.889,34$ & $9.942 .695,28$ & $2.552 .042,24$ & $25.866 .919,67$ \\
\hline 2029 & $10.945 .592,87$ & $363.889,34$ & $10.581 .703,53$ & $2.425 .053,34$ & $28.291 .973,01$ \\
\hline 2030 & $11.624 .219,63$ & $363.889,34$ & $11.260 .330,29$ & $2.304 .086,67$ & $30.596 .059,68$ \\
\hline 2031 & $12.344 .921,25$ & $363.889,34$ & $11.981 .031,91$ & $2.188 .889,74$ & $32.784 .949,42$ \\
\hline 2032 & $13.110 .306,36$ & $363.889,34$ & $12.746 .417,02$ & $2.079 .216,73$ & $34.864 .166,14$ \\
\hline \multicolumn{2}{|c|}{ Valor Presente Líquido (R\$) } & $34.864 .166,14$ & & & \\
\hline \multicolumn{2}{|c|}{ Taxa Interna de Retorno (\%) } & 39 & & & \\
\hline \multicolumn{2}{|l|}{ Payback (anos) } & 4 & & & \\
\hline
\end{tabular}

Nota: ${ }^{1}$ Adotada taxa de crescimento ao ano de 6,2\% e Taxa Mínima de Atratividade de $12 \%$ ao ano

O índice benefício/custo $[\mathrm{B} / \mathrm{C}]$ resultou no valor de $2,9734(\mathrm{R} \$ 52.530 .925,37 / \mathrm{R} \$ 17.666 .759,22)$. Neste caso, cada R\$ 1,00 investido na implantação deste projeto, proporcionou um rendimento de $\mathrm{R} \$ 2,97$, resultado que demonstrou elevada alavancagem do empreendimento. O projeto apresentou um VPL de R $\$ 34.864 .166,14$, que demonstrou o montante de riqueza obtida pelo investidor além do capital investido quando encerrado o projeto. A TIR, por sua vez, apresentou o valor de 39\%, demonstrando a alta lucratividade do projeto, uma vez que supera consideravelmente a TMA adotada a priori. O Payback seria obtido no $4^{\circ}$ ano do projeto, prazo 
também bastante inferior ao máximo estabelecido para investimentos dessa categoria (Gold, 1998).

De maneira geral, estudos de viabilidade econômica da área de infraestrutura de transportes apontaram como satisfatórios e atrativos projetos que apresentaram resultados econômicos que tem seu Payback realizado até a metade da vida útil do projeto e que consequentemente tem sua TIR e VPL ideais superados. Neste trabalho em particular, os valores dos índices econômicos de Payback ideal, TIR ideal e VPL ideal foram amplamente superados, tendo suas metas de viabilidade atendidas, demonstrando que o projeto proposto resultou em alta viabilidade econômica.

Além dos resultados de indicadores econômicos, é importante frisar que a principal implicação desses resultados foi o menor custo para a sociedade de investri em melhorias das rodovias ao invés de arcar com os desembolsos gerados no sistema de saúde pelos acidentes de trânsito. E essa dedução não requer sequer o apelo ao imensurável valor das vidas salvas com essas melhorias; demostrou ser economicamente viável simplesmente considerando-se o aspecto monetário do projeto. Cabe maior atenção por parte dos formuladores de políticas públicas e demais agentes envolvidos para que tais implicações sejam levadas em consideração quando da aprovação de projetos de melhoria das estradas ou mesmo da elaboração dos contratos de concessão de rodovias brasileiras.

Todavia, é preciso tomar os devidos cuidados com a generalização do uso da solução de área de escape para toda e qualquer pista descendente de serra com rampa de descida acentuada, visto que, devem ser comparados com outras possíveis soluções técnicas os resultados da eficiência na redução de acidentes e a viabilidade econômica destas outras alternativas.

$\mathrm{Na}$ serra estudada, por exemplo, seria possível comparar a área de escape proposta, com a alternativa de reconstrução total da pista de descida da serra com traçado geométrico adequado e também com a alternativa de implantação de uma nova sinalização altamente ostensiva em toda a serra. Talvez os resultados dos índices econômicos resultantes nas outras alternativas se apresentem muito similares aos da proposta da área de escape e, então, a escolha da solução a ser adotada se basearia no número total de acidentes evitados e no número total de redução de mortos acumulados ao longo da vida útil do projeto.

Em tempo, ainda que se possa intuitivamente imaginar que a eficiência, em termos de redução total de acidentes e mortos da solução via reconstrução da serra seja maior que da solução sinalização ostensiva e que, por sua vez, maior que da solução área de escape, ainda assim não há demérito na utilização da solução proposta, posto que todos seus resultados de redução de acidentes, redução de mortos e índices da viabilidade econômica apresentaram valores muito promissores.

Tendo em vista que as possíveis alternativas de soluções técnicas podem ser adotadas de forma isolada ou mesmo conjuntamente para resolver o problema aqui levantado e que cada uma das possíveis soluções técnicas tem uma enorme gama de variação em seus possíveis resultados de eficiência técnica e econômica, sugere-se que outros estudos abordem a viabilidade econômica de áreas de escape comparando com outras soluções técnicas que também resolvam o problema de mortes e acidentes de devido à perda do sistema de freios em pista descendente de serra com rampa de descida acentuada.

\section{Conclusão}

A solução proposta de área de escape para o $\mathrm{km}$ $667+300$ da BR-376/PR é viável economicamente, destaca-se que é menos custoso investir em melhorias de tráfego neste caso do que arcar com os custos dos acidentes gerados por essas adversidades das rodovias.

Valores muito baixos no número total evitado de acidentes ou veículos e pessoas envolvidas nos acidentes e mesmo uma baixa redução do número de vítimas fatais podem inviabilizar economicamente o uso de área de escape como alternativa de projeto. Todavia, a área de escape se mostra como uma solução viável ao problema.

Recomenda-se que outras soluções de engenharia podem e devem ser avaliadas, técnica e economicamente, para comparar diretamente com a solução de área de escape em locais com elevado número de acidentes e mortes devido à perda do sistema de freios em pista descendente de serra com rampa de descida acentuada. Recomenda-se, o estudo comparativo ocorra entre pelo menos três alternativas de soluções de engenharia, comparadas isoladamente e/ou associativamente para tomada de decisão da alternativa mais adequada.

\section{Referências}

Arteris. 2006. Relatório Anual Arteris S.A. Disponível em: $<$ http://ri.arteris.com.br/ptb/s-4-ptb-2007.html>. Acesso em: 20 set. 2016.

Arteris. 2016. Relatório Anual Arteris S.A. Disponível em: $<$ http://ri.arteris.com.br/ptb/s-4-ptb-2017.html>. Acesso em: 20 set. 2016.

Departamento Nacional de Infraestrutura de Transportes [DNIT]. 1999. Manual de Projetos Geométricos de Rodovias Rurais. Disponível em: <http://ipr.dnit.gov.br/normas-emanuais/manuais/documentos/706_manual_de_projeto_ geometrico.pdf>. Acesso em: 10 set. 2016.

Departamento Nacional de Infraestrutura de Transportes [DNIT]. 2016. Plano Nacional de Contagem de Tráfego [PNCT]. Disponível em: <http://servicos.dnit.gov.br/ dadospnct/Relatorio/Volume'TotalDiario $>$. Acesso em: 10 set. 2016.

Fukuchi, M.K.; Monteiro, T.; Canale, B.F.; Ortega, F.; Canale, 
A.C. 2015. Uma interpretação da NBR 10967 quanto aos requisitos para veículos comerciais trafegarem em declives longos e acentuados. Disponível em: <http:// pdf.blucher.com.br.s3-sa-east-1.amazonaws.com/ engineeringproceedings/simea2015/PAP183.pdf $>$. Acesso em: 24 ago. 2017

Gava, N.W. 2016. Estudos de tráfego para análise da seção operacional da pista na aproximação da Área de Escape do km 667+300 da BR-376. Canhedo Beppu Engenheiros Associados, São Paulo, SP, Brasil.

Gold, P.A. 1998. Segurança de Trânsito - Aplicações de Engenharia para Reduzir Acidentes. Banco Interamericano de Desenvolvimento [BID], Washington, D.C., USA. Disponível em: <https://publications.iadb.org/bitstream/ handle/11319/406/SEGURANCA_DE_TRANSITO_

Aplicacoes_de_Engenharia_para_Reduzir_Acidentes_por_ Philip_Anthony_Gold2.pdf? sequence $=2 \&$ is Allowed $=\mathrm{y}>$. Acesso em: 24 set. 2016.

Hirai, W.T. 2015. Projeto Executivo da Área de Escape do km 353+000 da BR-116 - Setenge - Serviços Técnicos de Engenharia S/C. Ltda. Autopista Régis Bittencourt S/A, São Paulo, SP, Brasil.

Instituto de Pesquisa Econômica Aplicada [IPEA]; Departamento Nacional de Trânsito [DENATRAN; Associação Nacional de Transportes Públicos [ANTP]. 2006. Impactos Sociais e Econômicos dos Acidentes de Trânsito nas Rodovias Brasileiras. Disponível em: <http:// www.perkons.com.br/pt/estudos-e-pesquisas-detalhes/63/ impactos-sociais-e-economicos-dos-acidentes-de-transitonas-rodovias-brasileiras>. Acesso em: 10 set. 2016.

Organização das Nações Unidas [ONU]. 2011. Década de Ação pela Segurança no Trânsito (2011-2020). Disponível em: <https://nacoesunidas.org/campanha/segurancatransito/>. Acesso em: 12 ago. 2016.

World Health Organization [WHO]. 2016. Addressing the challenges of the United Nations Decade of Action for Road Safety (2011-2020): outcome of the second Global High-level Conference on Road Safety - Time for Results. Disponível em: < http://apps.who.int/gb/ebwha/pdf_files/ WHA69/A69_R7-en.pdf?ua=1\&ua=1>. Acesso em: 24 ago. 2017. 